\title{
Barriers to Career Advancement for Female Engineers in Australia's Civil Construction Industry and Recommended Solutions
}

\author{
Taylah Bryce, Harry Far* and Anne Gardner \\ School of Civil and Environmental Engineering, Faculty of Engineering and Information Technology, University of \\ Technology Sydney (UTS), Australia
}

\begin{abstract}
This study explores the challenges that have emerged from the outdated and inflexible workplace culture of the civil construction industry, and how it is affecting female engineers and women in other functional site roles. The study primarily explores issues such as the strong culture of long work hours, the perception of staff who pursue work-life balance, and the perception of part time and flexible working options within the industry. The study was conducted over three phases where members of the industry answered questionnaires on the workplace issues listed above. The first phase aimed to document a female perspective on the construction workplace culture while the second phase focused on the perceptions of the same respondents regarding the industry's attitude to worklife balance and whether any of the aspects of workplace culture has discouraged them from staying in the industry. The final phase included men and women in management and employer roles to determine their views on part time and flexible working options within the industry. The results of the study are presented and discussed before recommendations are offered for contractor organisations, their employers and staff. The recommendations have been addressed in a way that a gradual culture change can be accepted and acted on throughout the entire workplace.
\end{abstract}

Keywords: Workplace culture, Male-dominated Industry, Part time and Flexible Work, Work-life Balance

\section{Introduction and background}

Key issues that have always been present in the civil construction industry are the culture of long work hours ingrained in the work ethic of the professionals, the significantly male dominated workplace, and a lack of functional on-site roles available with part time and flexible hours (Professionals Australia, 2010). A typical day on a civil construction site in the private sector will start at 6:30am for prestart and continue through to $6 \mathrm{pm}$. It is common during peak phases in construction for engineers to work on the weekend in addition to during the week. These issues do not present ideal working conditions for females entering this workforce. They are not ideal working conditions for males either, but it appears that women are less willing than men to tolerate such outdated, inflexible, and ultimately unproductive, working conditions, especially when they start families and need a staged return to work (Chappell and Galea, 2016). As a result, this industry sees low participation rates among female engineers. Statistics from the last 10 years show that only $11.8 \%$ of all employees in the Australian civil construction industry are female, and $16 \%$ of management positions within this industry are filled by females (Australian Human Rights Commission, 2013). Amaratunga et al (2006) pointed out that the major barriers for women entering and remaining in the civil construction workforce have been identified as the image of the industry, career knowledge, culture and 
working environment, family commitments, male dominated training courses and recruitment practices. Professionals Australia (2010) added that issues in the workplace persist, especially regarding workplace culture (including harassment) and inflexibility, pay inequality, and perceptions of the abilities of women to perform the same roles as their male counterparts.

Data from the Australian Bureau of Statistics (2013) (see Figure 1) shows that at least 89\% of engineers and $98.3 \%$ of engineering related trade workers are male. Furthermore, a far higher proportion of male and female full-time workers exists in the civil construction industry compared to part time workers. Only $1.8 \%$ of female engineers and $0.4 \%$ of females in an engineering trade work part time. When comparing this field of work to other occupations such as medical industry, where part time work for females is at $21 \%$, this industry is severely lacking in meeting the needs of this demographic (Australian Bureau of Statistics, 2013).

Despite the progress made in women's rights and their strong presence in the workforce by the commencement of the 21 st century, women still seem to be at a disadvantage in the civil engineering workforce. Mills et al (2014) stated that women are overrepresented in the lower levels of the workplace, and severely underrepresented in positions of management and regardless of significant advances in knowledge and power in the medical and law professions, somehow the women in engineering have been left behind.

Mills et al (2014) raised the major social issue that in Western culture, women are the ones who are tasked with the vast majority of the responsibility of caring for children. This significant amount of unpaid labour leads to a reduced amount of time and freedom needed to engage in full time, challenging work. This reduces women's choice in the types of paid work available to them. Amaratunga et al (2006) supported this point by noting that in Britain just $9 \%$ of women hold jobs in the civil construction industry. However, $84 \%$ of those women work in secretarial jobs, $10 \%$ are employed at a professional capacity, and the remaining $6 \%$ are working at trade level. So, despite the breakthrough of women joining the civil construction industry, most of these women are still performing traditional gender work roles (Amaratunga et al, 2006). In line with these findings, as illustrated in Figure 2, in a survey conducted on women in the STEM professions by Professionals Australia (2015), respondents stated that they experienced a lack of access to senior roles for women. Additionally, results from the study showed consistent feedback about the inability to re-enter the workforce after taking time off for maternity leave. $70.3 \%$ of respondents stated that taking this time off had a negative impact on their career and $21.3 \%$ stated they had been passed over for a promotion due to their parental leave break (Professionals Australia, 2015). 
However, it is not all bad news. The Centre for Work and Life published a study presenting solutions for work-life balance innovations in Australian workplaces. A major national contractor, Probuild, was one of the selected workplaces for the study (McMahon \& Pocock, 2011). This company took on an innovative approach to work practices to reduce the attrition rates of employees and wage staff, and to increase productivity and job satisfaction within the company. Results from their employee satisfaction survey showed that poor work-life balance was the main reason for dissatisfaction. This resulted in a consultation with the managers to discuss a culture change within the workplace. The changes were introduced in stages, allowing managers to become accustomed to the alterations in the workplace culture. Managers were provided with the outline of a flexible, work-life balance plan which they were required to tailor to suit their workplace environment. This initiative started a shift in the attitudes among the managers, which led to a more approachable environment that stimulated conversations with employees about work plans that suited everyone.

With many female graduates accepting their engineering bachelor's degree just a few years away from the average Australian child bearing age of 28.9 (AIHW, 2017), many challenges may arise concerning how these women will manage to raise a family and build a successful career as civil engineers while also feeling equal to the task beside their male colleagues. It has become apparent that the long-hours culture, along with the inflexibility to work part time hours for site roles present a significant obstacle in achieving a successful balance between work and other aspects of life. In light of this, this study has posed the following questions:

- Are the attrition rates in the engineering profession higher for women than men due to traditional family roles?

- Is there a difference in workplace roles that women return to when coming back from a career break compared to when they left? If so, are those roles as challenging as the roles women returning to work had previously?

- What jobs can become more available to women in an engineering context when they return to work in a flexible or part time role? and finally,

- What strategies can be put in place to make work in the civil construction sector easier to balance for women who are also mothers or carers?

\section{Study Methodology}

This study was conducted primarily through three phases of questionnaires using an online data collection site. The questionnaires contained a mixture of closed-form and open-ended 
responses. The first and second phase targeted female engineers and females performing functional site roles such as: safety, environmental, commercial, quality, administration, and surveying in the Australian civil construction industry. All respondents were recruited via an email sent out by project directors of leading Australian civil construction companies with a message detailing the purpose of the study, details of what was required from participants, and a link to an online registration form. Both questionnaires were sent out to 90 respondents and received a $91 \%$ response rate. This outstanding response rate is way higher than typical survey response rates which indicates the strong desire of the participants to be heard. The purpose of the first phase of the study was to document the experiences of women in the civil construction industry and to determine their perspective on the construction workplace culture. The purpose of the second phase of the study was identify trends in respondents' views regarding female retention rates and career progression within the construction industry. This questionnaire focused on aspects of workplace culture that may cause the respondents to consider leaving the industry. The second phase of the study was targeted to the same respondents in phase 1 of the study. The second phase received an $80 \%$ response rate. The final phase of the study was addressed to both genders who held positions in management and human resources in the Australian civil construction industry. The purpose of this phase was to determine the general views of management regarding the acceptance of flexible and part time work practices within the construction industry. The third phase was released to 158 professionals and received a $47 \%$ response rate.

\section{Findings}

Descriptive statistics were used to analyse the closed form responses to the questionnaires with comments from open-ended responses being used to provide additional insight and the respondent's voice.

\subsection{Workplace Culture}

The most significant finding reported by respondents regarding workplace culture were the long hours spent at work each week. $41.5 \%$ of respondents stated that they always worked over time and $35.4 \%$ reported that they usually worked over time. The most common amount of contact hours selected by the respondents in phase 1 of the study were between $55-65$ per week. For complete results, refer to Figure 3 which illustrates the typical hours spent at work per week by the female respondents from phase 1 .

Furthermore, participants ranked the culture of long hours as the top reason why they are, or have previously considered, leaving the construction industry. A participant from the first and 
second study stated that: "the standard working day is ten hours plus travel and it is exhausting. I am working towards leaving the industry because the hours are simply too much."

\subsection{Representation of Women Across the Industry}

Of the 82 female respondents in the first survey, $59.3 \%$ of participants reported that there are significantly more males than females in their workplace, and a further $29.6 \%$ of respondents said that their workplace was more than $50 \%$ male dominated. Only $8.6 \%$ of respondents claimed to have a 50/50 ratio of males to females. The study results were further broken down into the individual participants' responses to compare their age group against how many years from now they intended to be working in the civil construction industry. This is illustrated in Figure 4. The results showed that female engineers, age 18 to 24 , were the least likely to see themselves working in the construction industry in 10 or more years' time. Respondents in the $35-44$ age group were the most likely to see themselves working in the civil construction industry after 10 years. Surprisingly, the respondents from the 2 oldest age groups did not select anything less than 5 years as an option, with the female engineers in 55 - 64 year age group reporting the highest number of years out of the two. However, due to the significantly lower numbers of women aged between 55 - 64 who responded to the study, the results may appear to be exaggerated.

Phase one of the study went onto explore the scarcity of female managers within the construction industry. $51.9 \%$ of respondents reported that they had never had a female manager in their workplace. Only $6.2 \%$ of respondents confirmed that they always had a female manager in their workplace. A female participant from study phase 1 and 2 stated that, "there are female managers in my workplace, although no female engineering managers. [There are] only support roles, i.e. community and commercial [managers]." Additionally, the results from phase 2 of the survey reported a total of $56.9 \%$ of respondents either disagreed or strongly disagreed that they had a senior female role model at work in whom they could seek guidance. This is compared to $37.5 \%$ of respondents who reported that they did have a female role model senior to them who they could seek guidance from.

\subsection{Barriers to Career Advancement}

The study results from phase one show that just under one third of female participants have children. Of the participants who are mothers, $76 \%$ reported that their children needed care which reduced the respondent's availability to work. Over half (51.2\%) of female respondents from the phase one study were categorised into the $25-34$ age group. With the average age of 
Australia's first-time mother being 28.9 years old (AIHW, 2017), the number of respondents with children seems to be very low. The lack of women with children in this industry may potentially suggest that the workplace culture is not flexible enough for a work and family balance. Additionally, when asked about barriers to career progression due to family commitments, $62.9 \%$ of respondents from phase 2 agreed that they would have less choice in job roles in the civil construction industry after returning to work from maternity leave. When the same respondents were asked if having a child or another child would negatively impact their career progression, $64.8 \%$ agreed that it would. A female participant from phase 1 and 2 of the study expressed that she, as well as her other female colleagues, are currently putting off starting a family, because they are all concerned about the negative impact it will have on their careers.

The study went on to explore other barriers women faced in regard to their career advancement. Most respondents (60\%) from phase 1 and 2 believe that gender discrimination does occur during the awarding of promotions. Additionally, a total of $63.9 \%$ of female respondents from phase 2 reported that they felt they needed to prove themselves capable where their male colleagues were assumed capable. This issue could be a contributing factor for the gender discrimination felt among female respondents during their efforts to advance their career in the civil construction industry.

Figure 5 represents the main reasons why female participants are finding it hard to progress in their career. Although $41.4 \%$ have stated that this question is not applicable to them, the reason could be that they have not been in their position long enough to want a promotion, or their project has not been running long enough for promotion opportunities to present themselves. It could also mean that it is not applicable because they are not finding it difficult to progress. However, the highest actual issue recorded was the lack of roles and job opportunities available, which came in at $14.3 \%$. This was followed by workplace culture at $10 \%$, and balancing work and life responsibilities at $8.6 \%$.

\subsection{Part time and Flexible Work Patterns}

Of the women in phase 1 of the study who were mothers and had returned to work, $47.8 \%$ held the same position as they had before they left and $34.8 \%$ held a job that was not related to their previous role. Only $8.7 \%$ had a job that required more knowledge and skill than their previous position, and the same percentage now held a job that required less knowledge and skill than their previous position. The results from the women in phase 2 indicate a poor image of how 
their employer or workplace would react to part time work. A total of $76.0 \%$ either agreed or strongly agreed that working part time either has had a negative impact or would have a negative impact on their career. Additionally, very few (4.2\%) of those female respondents from phase 2 believe that they would not miss out on career opportunities by working part time. In contrast, most managers from the third phase of the study disagree with the views of the respondents from phase 1 and 2 . The study reports that $60.8 \%$ of managers disagree with the statement, "If workplace flexibility allows staff to work $50 \%$ of the week, this means that experience and career potential will grow only at the same rate, i.e. $50 \%$ compared to an employee who works full time". However, just because they disagreed with the statement it doesn't mean they would offer part-time work or that they would not discriminate because of it, unfortunately.

In terms of work-life balance offered in the civil construction industry, respondents from phase 2 of the survey disagreed that they could achieve this goal in their workplace. A total of $71.8 \%$ of respondents either agree or strongly agree that trying to achieve a work-life balance has either impeded or would impede their career development. Additionally, the respondents were asked about whether the nature of their career has negatively affected their relationships outside of work, as well as their plans for motherhood. The overall result was rather negative with a total of $43.7 \%$ agreeing that their career impacted their plan for parenthood, and $52.8 \%$ agreeing that their career impacted their personal relationships.

\subsection{Views of Management Regarding the Acceptance of Flexible Work}

In the final phase of the study, intended for management in the civil construction industry, $47.3 \%$ of respondents were male and $52.7 \%$ were female. This is not a representative distribution of gender in this industry. However, it appears that the female managers were more willing to participate as their response rate was almost $100 \%$ compared to $30 \%$ of the male managers invited. The study indicates that a total of $90.5 \%$ of employers agree that there would be a higher retention rate among female employees in the civil construction industry if more part time and flexible options were offered. Figure 6 was derived from the study results to display a ranking system in which the respondents determined the role that would be the most achievable in a part time and flexible scenario. Unsurprisingly, the managers and HR representatives ranked administration as the most achievable part time position and engineering management as the least achievable. 
Respondents from phase 3 of the survey rated reasons from most applicable to least applicable as to why the most difficult role (chosen above) would be hard to do on a part time basis. The results, rated in descending order of importance were: frequent project deadlines, daily or frequent program changes, continuity, team meetings and interactions, ownership of tasks, long hours required to complete daily activities, team dynamics, and meeting KPIs. In terms of the type of part time and flexible options available, respondents rated, in descending order of achievability, the type of arrangements which would be the most achievable in a site setting for functional roles - these are summarised in Figure 7.

Considering the acceptance of part time and flexible working practices during staff recruitment periods, this study has shown that workers seeking this work status may not even be considered for the role. Of the respondents from phase 3, 60.3\% agree that employers are likely to be biased against workplace flexibility requests during interviews for new staff. However, the situation seems to change once staff have been employed full time. A total of $90.6 \%$ of respondents agree or strongly agree that they would be open to a discussion with their employees regarding changing to flexible or part time work positions.

In terms of bringing productivity and value to the project teams, the following figures demonstrate positive results. A total of $62.2 \%$ of the respondents from the third phase of the study agree or strongly agree that flexible work practices generate a higher output per hour from employees compared to employees working constant long hours. Additionally, $97.3 \%$ of respondents agreed that recognising an employee based on their results and progress rather than their hours spent at work is a better way of measuring commitment to the project. One of the third phase respondents stated that "as a senior manager, I have observed that female engineers are coming through the ranks and far outshining their male counterparts in intellect, drive, attention to detail and motivation. The industry needs to harness this and offer the flexibility to enable a long-term solution for retention."

\section{Recommendations}

Based on the key arguments raised in the literature review, the results of the survey questions, and discussions with leading Australian civil construction companies, the following recommendations to private civil construction organisations as well as the governing bodies who direct such organisations can be offered:

\section{Recommendation 1}

Contractor organisations could actively encourage working days of maximum 10 hours and discourage field staff and office employees to work Saturdays unless absolutely necessary. This 
informal directive, if enforced regularly and practiced in a top down approach, will encourage workplace culture to change from a 'presenteeism' approach to a workplace that values a healthy work-life balance.

\section{Recommendation 2}

Studies show that female employees are "primarily motivated by their participation in actual projects, complemented by support from role models" (AWPA, 2014). Contractor organisations could develop a mentoring program directed at all graduate and site engineers of both genders to encourage professional and personal growth. Mentoring helps mentees to form a strong relationship with a senior professional, form a network within the industry, speak up about issues, better understand their organisation, and progress in their career (Management Mentors, 2018).

\section{Recommendation 3}

The Department of Employment (2017) has stated that there is a shortage of civil engineers in NSW, especially in Sydney. According to their study, $60 \%$ of vacancies were filled in the NSW engineering sector overall, and just 38\% in Sydney. Employers should consider filling these vacancies by advertising part time and flexible work positions. These alternative working options will open the door to many other resource pools such as mothers planning a phased return to work, older persons wishing to pursue their career part time, and other persons with carer responsibilities. The construction industry will fill gaps in talent, skill and knowledge from a sector of the population that has been previously overlooked.

\section{Recommendation 4}

Employers should consider providing remote access to the project's intranet and project folder drives, cloud-based project collaboration system such as TeamBinder, and video chat tools that are now readily available and widely accepted. Much of the paperwork and office activities that take up a significant portion of the working day can easily be completed at home. Part time and flexible work can be achieved, including at an engineering capacity, with staff working part of their week at home. This is especially advantageous for working mothers and others with carer responsibilities. An example of a flexible agreement may include allowing a functional site team member (such as a site engineer) to work 3 to 4 days in the office, with one or two remaining days at home where she may focus on office tasks such as project quality documentation and costing summaries. Working from home can be advantageous as productivity and efficiency on site are often hindered by constant interruptions.

\section{Recommendation 5}


For an on-site role such as engineering, the 9am to 3pm work day and the job share 3-day week with an overlap seem to be the best options as the window of absence can be recovered if the program shifts. The job share option would work best when a staff member works Monday to Wednesday and her colleague works Wednesday to Friday. The information handover will occur on the Wednesday as well as any necessary team meetings. Essentially, a 6-day working week is completed in 5. The 9am to 3pm work day could work best when site inspections and approvals occur during those hours. Construction activities such as a concrete pour may occur outside these hours as it is likely the engineer will be present for some of it. Team leaders can embrace a flexible attitude among their team and look to organise another staff member within the same project team to supervise the activity on the occasion that it falls outside the core work hours.

\section{Recommendation 6}

It is recommended that construction organisations place a higher value on the role of fathers in parenting and encourage fathers to take a more active role in parenting in the early years. This could be addressed by promoting flexible working arrangements to males as well as females. In turn, this may liberate women from bearing the majority of the pressure that comes with parenting and help them maintain continuity within their career.

\section{Recommendation 7}

Contractor organisations may choose to address part time work options in phases. Employers may actively advertise part time positions for project support roles such as administration, commercial and community relations. The act of doing so may encourage the process of change with moving more difficult roles into part time and flexible options. The following step will lead into normalising part time and flexible options for safety and environmental roles. Finally, a change of culture regarding the 'presenteeism' attitude will shift inside the organisation and project teams will be ready to assess the possibility of part time engineering roles.

\section{Recommendation 8}

Contractor organisations can consider producing a policy that helps facilitate a fair and structured discussion between employers and female employees regarding their return to work after maternity leave. The policy should aim to assist employers in considering the needs of their female staff who are planning a maternity break by encouraging a return to work plan. The employer and staff member may discuss their expectations upon her return to work before the maternity break commences and discuss any changes to the plan again prior to return. This will create a platform for the staff member to voice her needs and concerns regarding her career 
progression and work-life balance.

\section{Recommendation 9}

Where possible, start-early, finish-early and/or start-late, finish-late arrangements could be incorporated into the project teams. This will allow for a potential school pick up or drop off sharing arrangement with a staff member's partner as well as an opportunity for household and carer responsibilities to be shared between parents. An arrangement such as this will have less impact on the continuity and dynamic nature of workplace as the employee will be present during the peak period of the working day.

\section{Recommendation 10}

Many part time employees state that they miss out on training opportunities that would benefit their career due to the training sessions being conducted outside their working hours or days (Professionals Australia, 2015). Where possible, project managers may consider running online training to allow maximum number of employees to gain access and benefit at a time that suits them. Alternatively, where online training may not be appropriate, employers could consider running two training sessions at alternative times and days. The result of these efforts will circle back to the project as more employees will bring additional knowledge and skill to the project. Better access to training for part time workers will also provide more opportunities for these staff to progress in their career and participate in a range of more challenging and meaningful roles.

\section{Conclusions}

The civil construction industry has historically been dominated by men in engineering professions and trades. Today, this continues to be the case with Australia seeing only $11.8 \%$ of women accounting for all employees in the construction industry, including administration roles. The major barriers faced by women in this industry include the long-hours culture, lack of senior female engineering professionals as role models, lack of access to part time and flexible work options, family and carer commitments, male dominated recruitment practices and the perception surrounding the abilities of women to perform the same roles as their male colleagues.

This study was carried out within the limits of the private sector of the civil construction industry via three phases of questionnaires. The first two phases of the study were directed at female professionals in functional site roles and the final phase of the study was directed at male and female site and corporate managers and human resource team members. Background 
research found that female engineers under the age of 50 were less likely to be employed if their age was between 24 to 40 . The study showed that $62 \%$ of the 25 to 34 age group were engineers or other functional site staff and, apart from the 18-24 age group, were the least likely to have children. This data suggests that women are dropping out of the construction workforce due to their traditional family roles, or they are not even considering having children until much later or at all. After these women return to work from maternity leave, the majority stayed in the same role as before they left, or they took a role that was not related to their previous job. Almost $40 \%$ of respondents were in a role that did not use their professional engineering skills and experience - these women are a lost resource in an industry reporting a shortage of professional engineering staff.

According to employers in the final study phase, on-site engineering support roles such as quality engineering, environmental engineering and surveying are the roles most amendable to part time work. Additionally, employers agree that engineering management in an office context is also achievable part time. The most likely part time solutions for these positions are job sharing, 4-day working weeks and start-early, finish-early and/or start-late, finish-late options. There is still a way to go with retaining women in engineering roles but changing an outdated and inflexible workplace culture will make an impact. 


\section{References}

Amaratunga, R.D.G., Haigh, R.P., Shanmugam, M., Lee, A.J. \& Elvitigalage Dona, N.D. 2006, 'Construction Industry and Women: A Review of the Barriers', University of Salford, Manchester, viewed 20 March 2018, <http://usir.salford.ac.uk/9877/1/176 Amaratunga RDG et al CONSTRUCTION INDUST RY_AND_WOMEN_A_REVIEW_OF_BARRIERS_3rd_SCRI_Symposium.pdf>

Australian Bureau of Statistics 2013, Australian Social Trends, Nov 2013, cat. No. 4102.0, ABS, Canberra, $\quad$ viewed $30 \quad$ April 2018, <http://www.abs.gov.au/ausstats/abs@.nsf/Lookup/4102.0Main+Features10Nov+2013>

Australian Human Rights Commission 2013, 'Women in Male-Dominated Industries: A Toolkit of Strategies', Australian Human Rights Commission, Sydney, viewed 10 March 2018, $<$ https://www.humanrights.gov.au/sites/default/files/document/publication/WIMDI Toolkit 2 013.pdf $>$

Australian Institute of Health and Welfare (AIHW) 2017, Australia's Mothers and Babies 2015 - in Brief, Perinatal statistics series no. 33, cat. No. PER 91, AIHW, Canberra, viewed 4 May 2018, <https://www.aihw.gov.au/getmedia/728e7dc2-ced6-47b7-addd-befc9d95af2d/aihw-per-91inbrief.pdf.aspx?inline=true $>$

Australian Workforce and Productivity Agency 2014, 'Engineering Workforce Study', Department of Industry, Canberra, viewed $20 \quad$ February 2018, $<$ https://docs.education.gov.au/system/files/doc/other/engineering-workforce-study-june2014.pdf $>$

Chappell, L. and Galea, N. 2016, Construction is the Last Frontier for Women at Work, Sydney Morning Herald, 6 December, viewed 17 April 2018, <https://www.smh.com.au/opinion/constructionis-the-last-frontier-for-women-at-work-20161206-gt4par.html $>$

Department of Employment 2017, Civil Engineering Professionals, April 2017, ANZSCO 233211,12,14,15, Labour Economics Office, NSW, viewed 15 May 2018, <https://docs.jobs.gov.au/system/files/doc/other/2332civengprofnsw.pdf>

Management Mentors 2018, 25 Benefits of Mentoring, Massachusetts, viewed 17 May 2018, < https://www.management-mentors.com/resources/benefits-of-mentoring>

McMahon and Pocock, 2011, Doing Things Differently: Case Studies of Work-Life Innovation in Six Australian Workplaces

Mills, J.E., Franzway, S., Gill, J. \& Sharp, R. 2014, Challenging Knowledge, Sex and Power: Gender, work and engineering, Routledge, Oxon

Professionals Australia 2010, 'Women in the Professions: The State of Play', Professionals Australia, Melbourne, viewed 20 March 2018, <http://www.professionalsaustralia.org.au/professionalwomen/wp-content/uploads/sites/48/2014/03/Womens-Survey-Report-web-2009-10.pdf>

Professionals Australia 2015, 'The Slower Track: Women in the STEM Professions Survey Report', Professionals Australia, Melbourne, viewed 3 March 2018, <http://www.professionalsaustralia.org.au/professional-women/wpcontent/uploads/sites/48/2014/03/2015-Women-in-the-STEM-Professions-SurveyReport.pdf> 


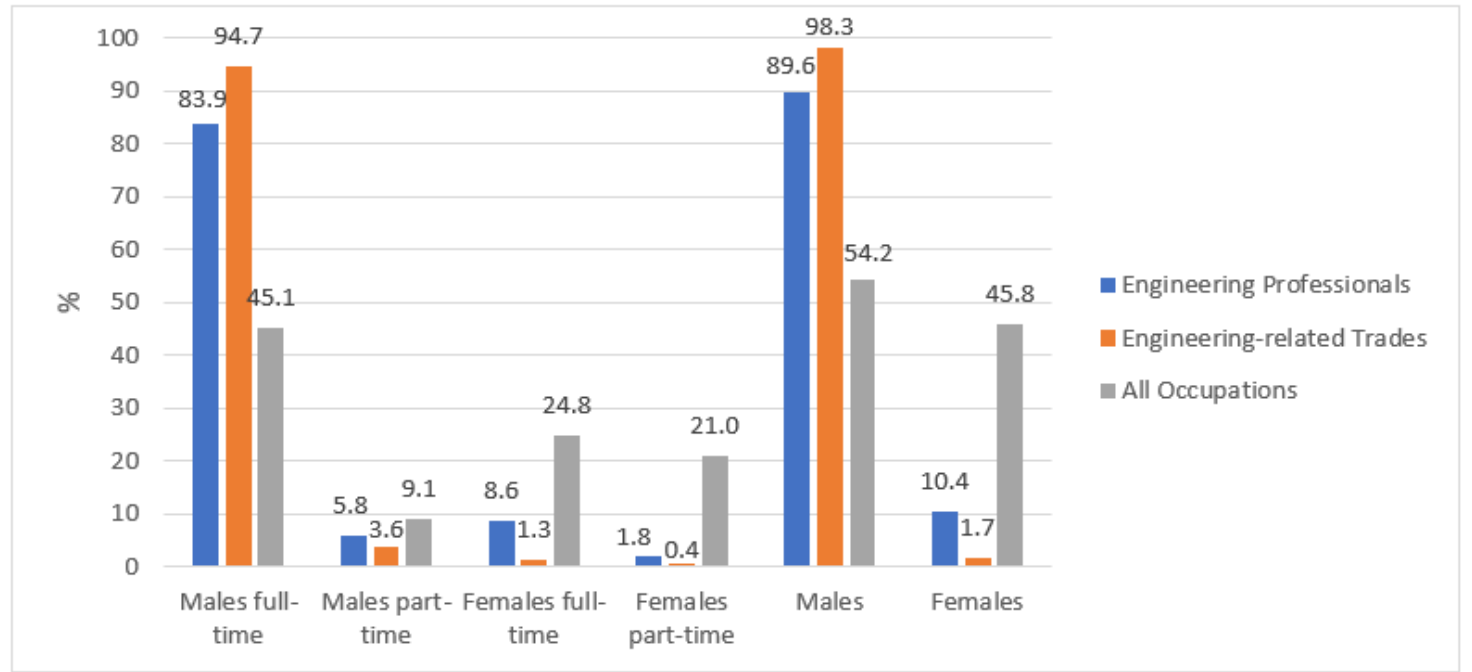

Figure 1: Gender profile for engineering professionals and engineering-related trades, 2013, four-quarter average (ABS, 2013) 


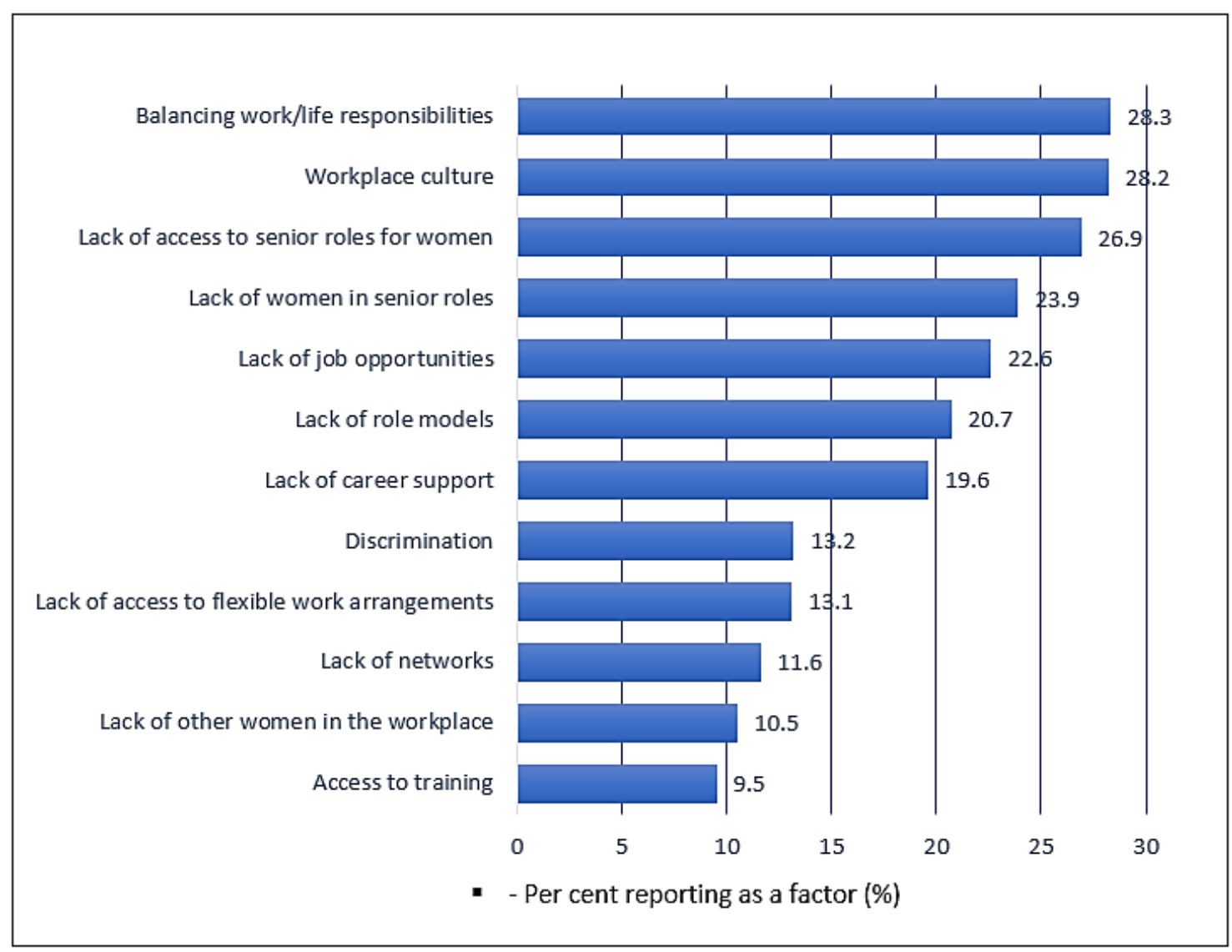

Figure 2: Barriers to Female STEM Professionals regarding Career Advancement (Professionals Australia, 2015) 


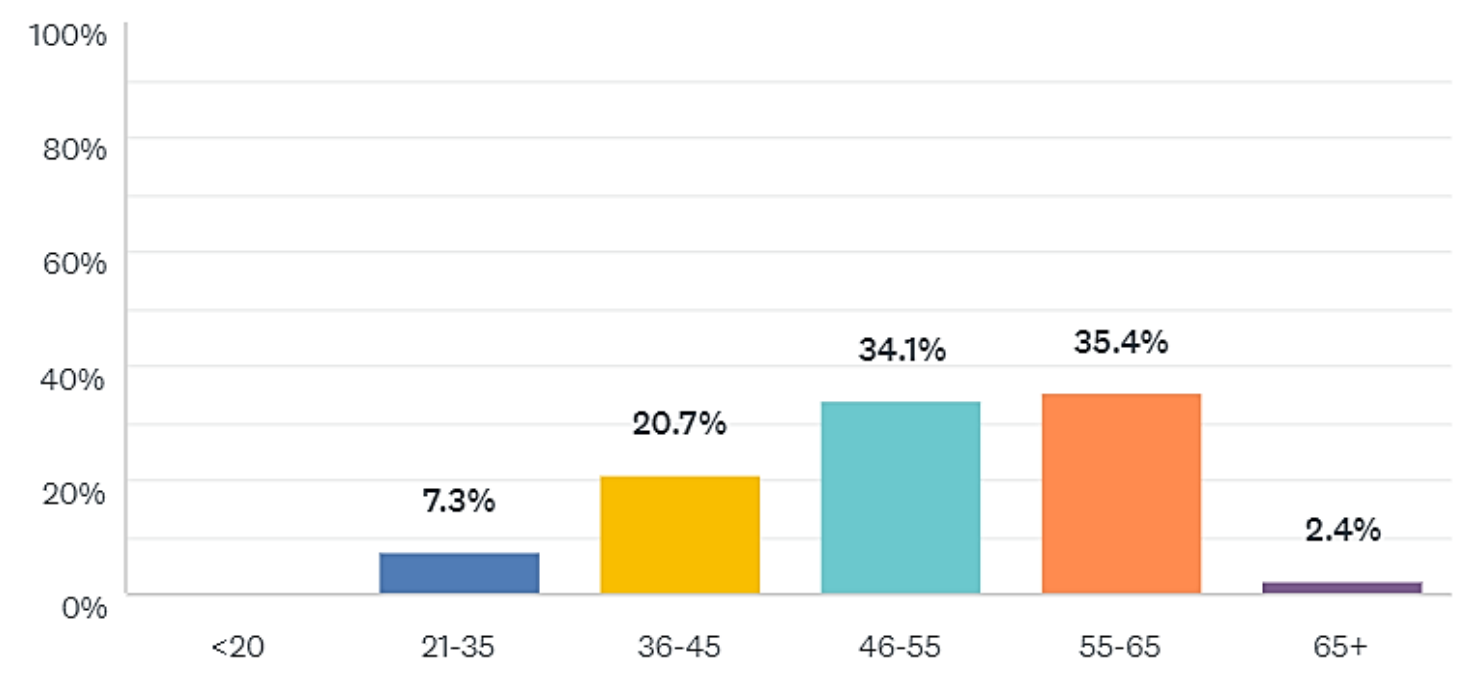

Figure 3: Results from phase 1- Typical hours per week respondents spend at work 


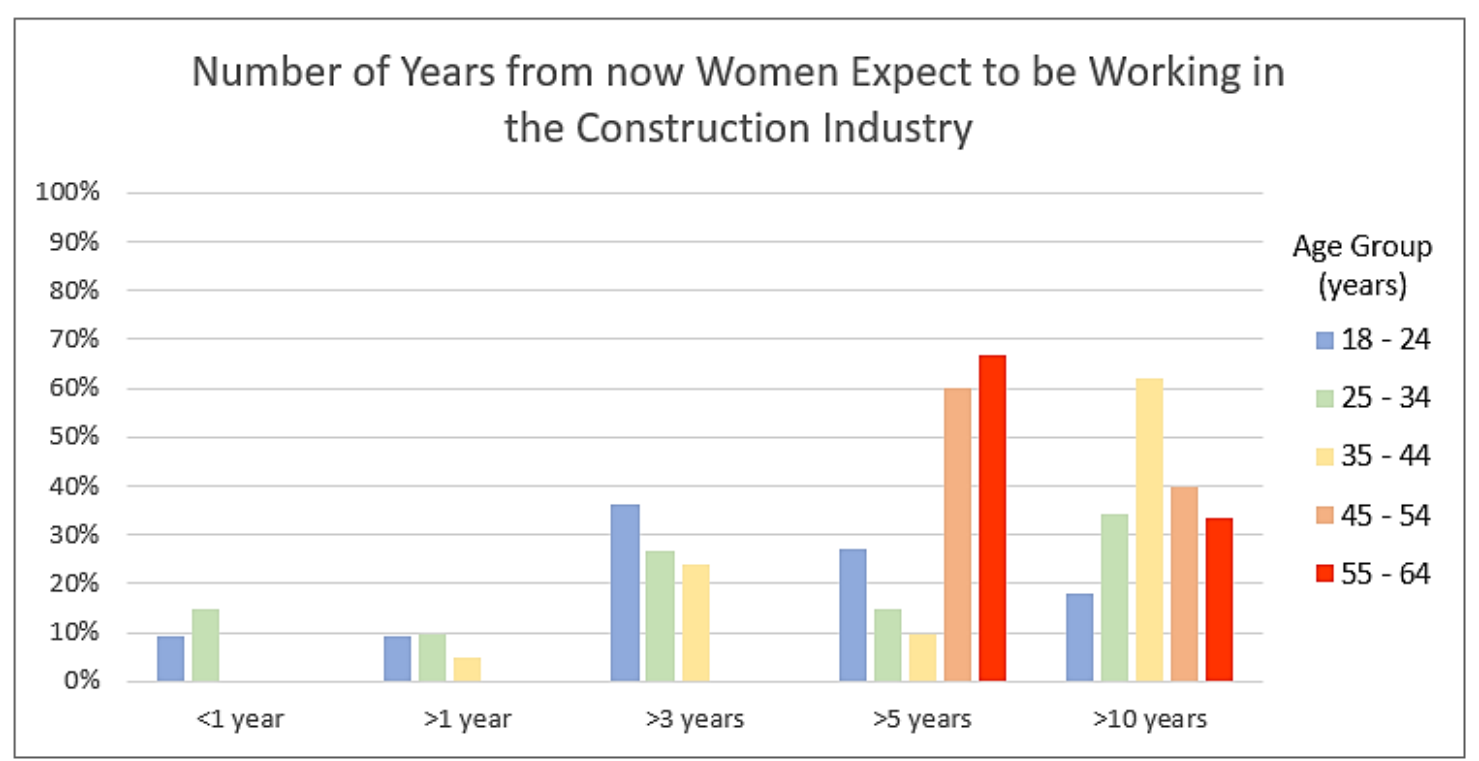

Figure 4: Results derived from Phase 1 - Number of years from now respondents expect to work in the construction industry by age group 


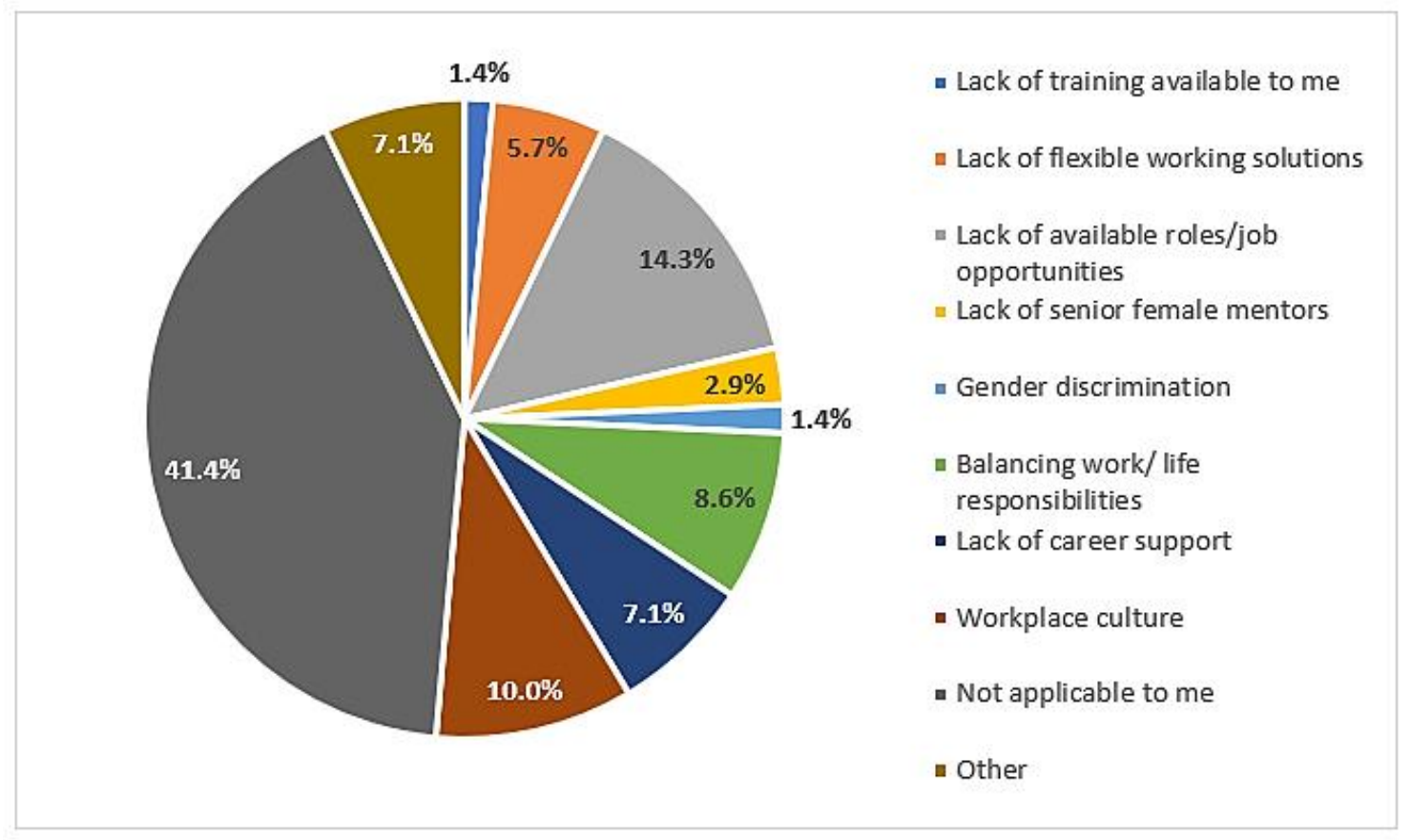

Figure 5: Results from phase 2 - Reasons why female respondents finding it difficult to progress in their careers 


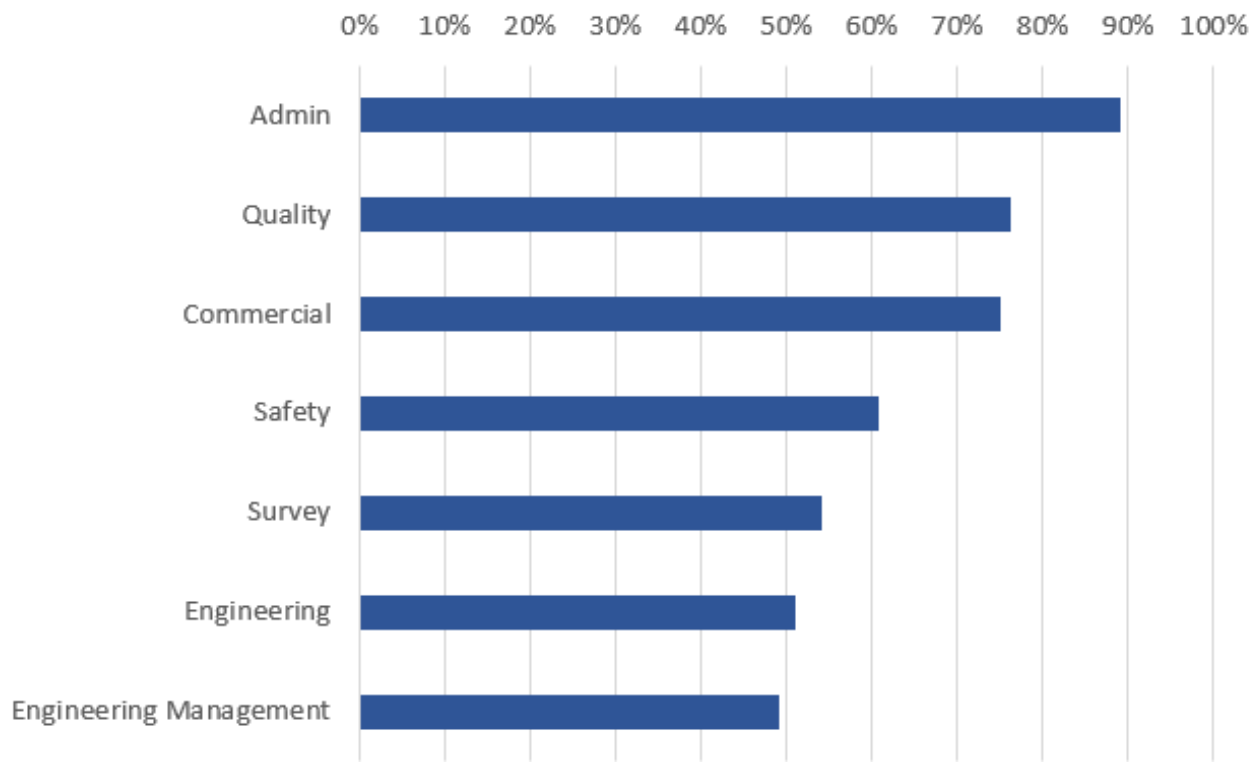

Figure 6: Derived from phase 3 results - Roles ranked from most achievable to least achievable if offered as part time or flexible positions 


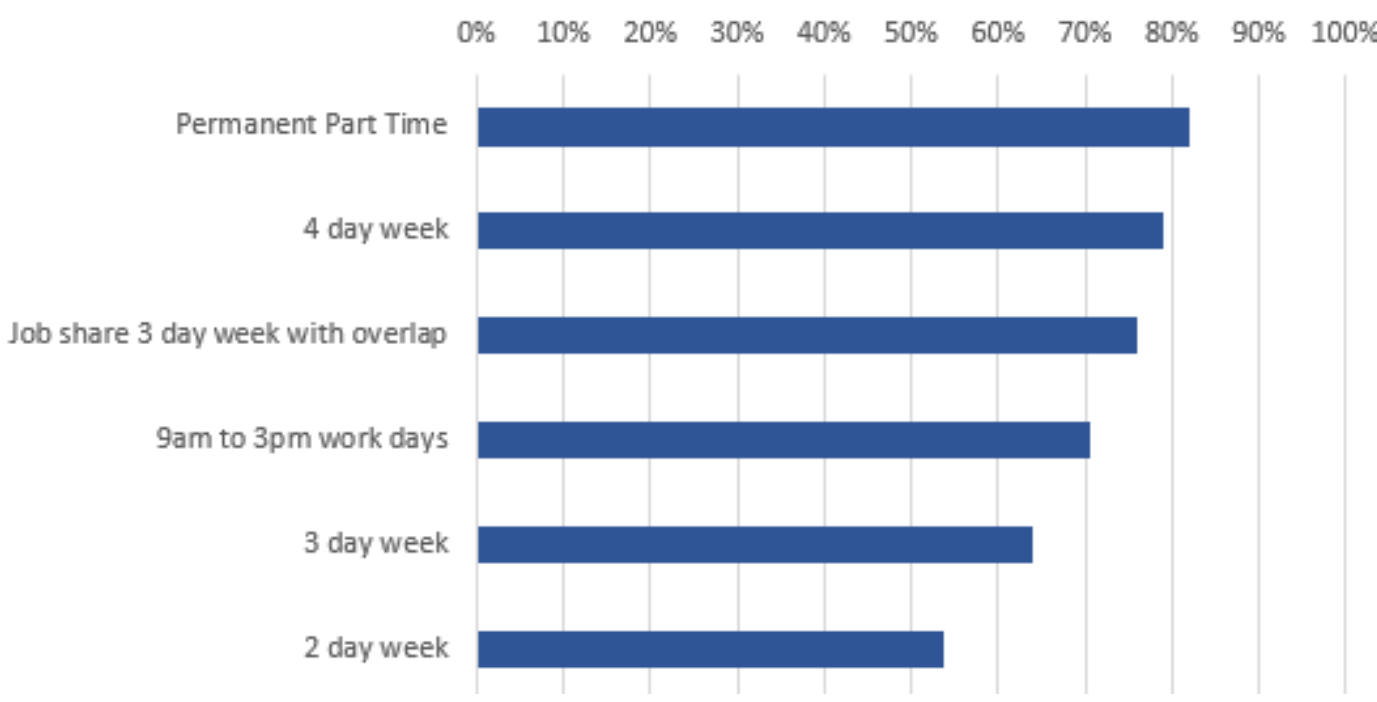

Figure 7: Results derived from phase 3 - Level of acceptance regarding the part time and flexible work options available that site projects can support 